\title{
Thermodynamic Measurements and Predictions
}

\author{
of the Adsorption of Short-chain Peptides on
}

\author{
Nanothin Polymer Films
}

\author{
Nripen Singh, Scott M. Husson* \\ Department of Chemical Engineering, Clemson University, Clemson, SC 29634-0909 \\ AUTHOR EMAIL ADDRESS: shusson@ clemson.edu

\section{RECEIVED DATE} \\ * To whom correspondence can be addressed. Tel.: (864) 656-4502. Fax: (864) 656- \\ 0784. E-mail: shusson@clemson.edu.
}

Supporting Information. Chemical structures are given for all of the peptides studied. 
Scheme 1. Structure of leucine-enkephalin (YGGFL)

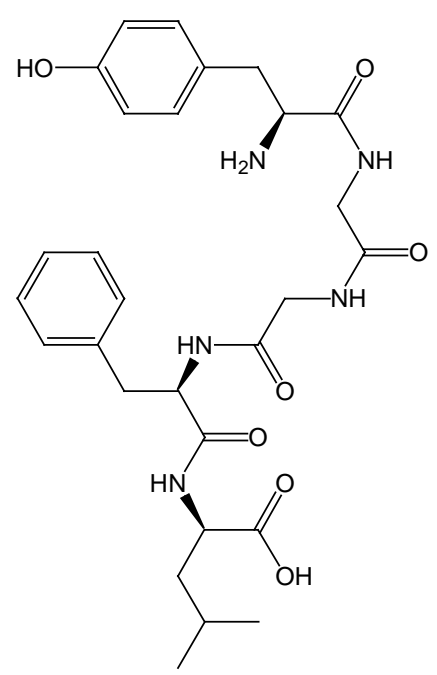


Scheme 2. Structures of (a) Tyr-Tyr (YY), (b) Tyr-Tyr-Tyr (YYY), (c) Tyr-Tyr-Tyr-TyrTyr-Tyr (YYYYYY).

(a)

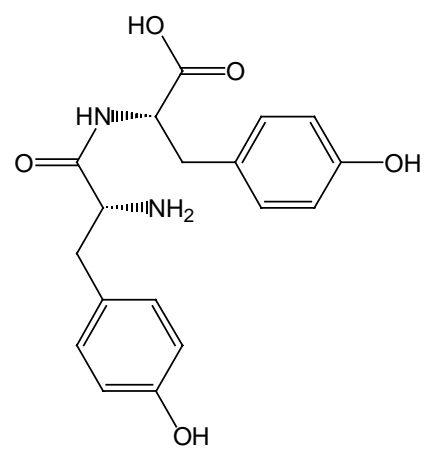

(b)

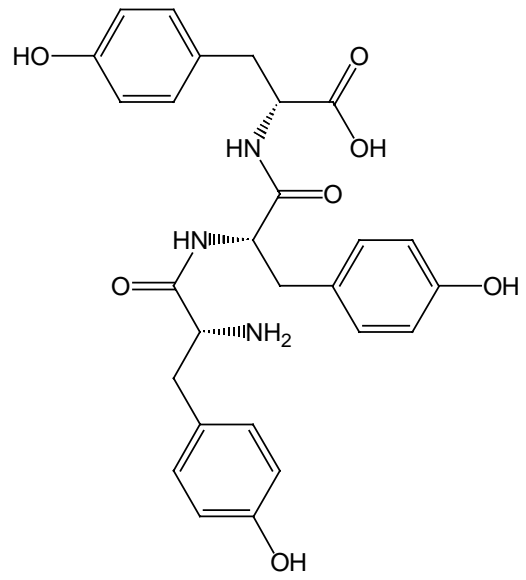

(c)

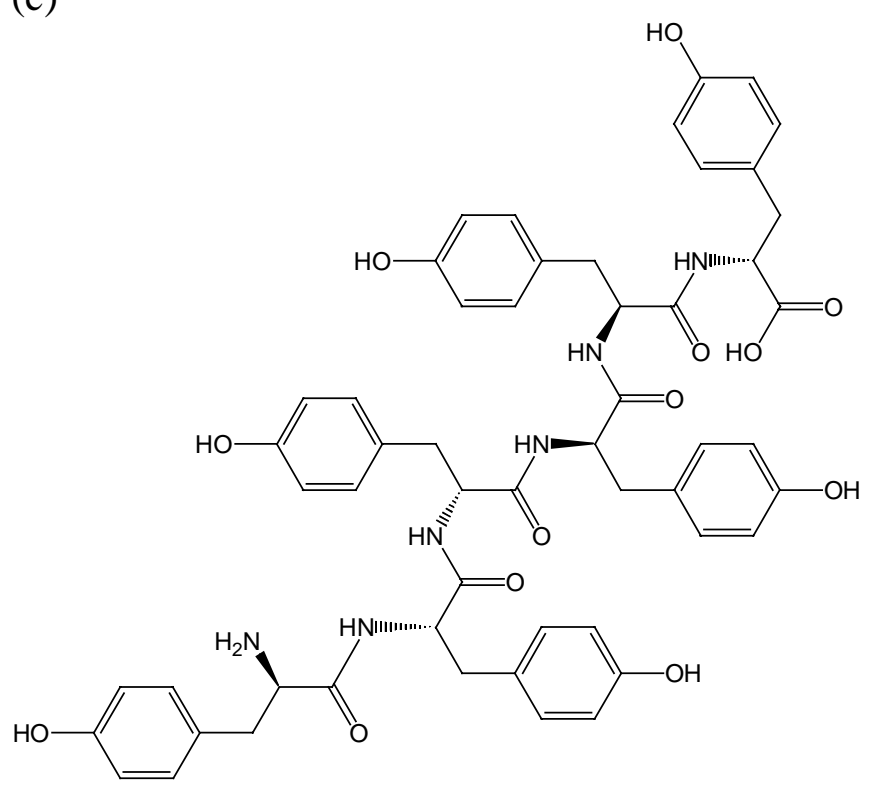


Scheme 3. Structures of (a) Phe-Phe (FF), (b) Phe-Phe-Phe (FFF), (c) Phe-Phe-Phe-Phe (FFFF).

(a)

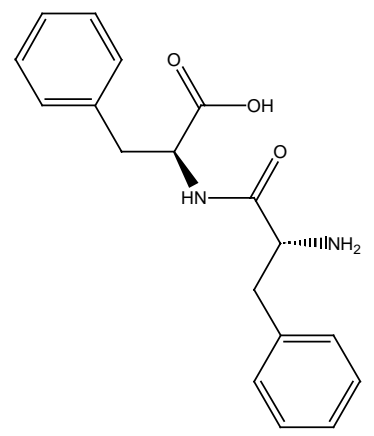

(b)

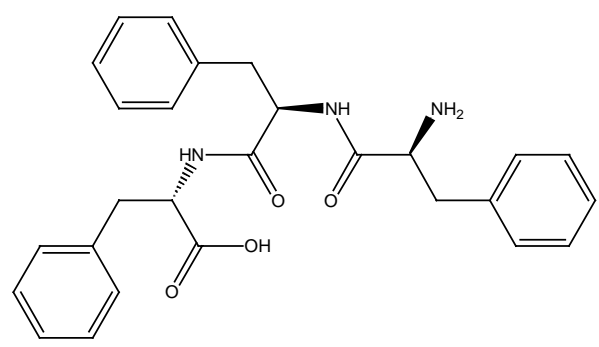

(c)

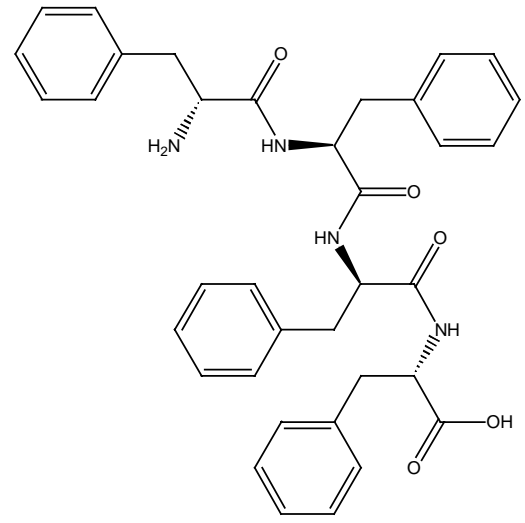


Scheme 4. Structure of (a) Gly-Gly-Gly-Gly (GGGG), (b) Gly-Gly-Gly-Gly-Gly (GGGGG), (c) Gly-Gly-Gly-Gly-Gly-Gly (GGGGGG)

(a)

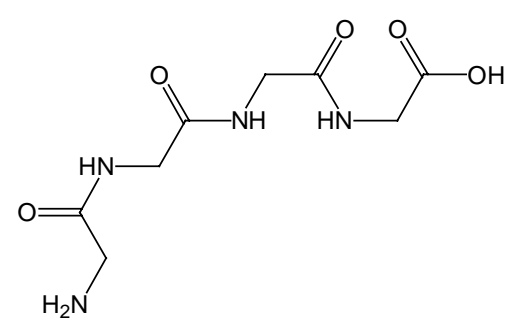

(b)

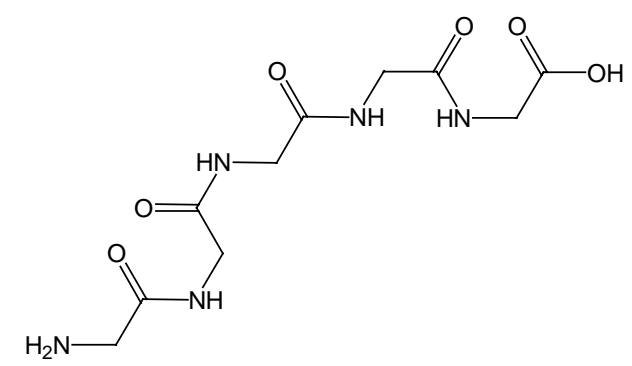

(c)

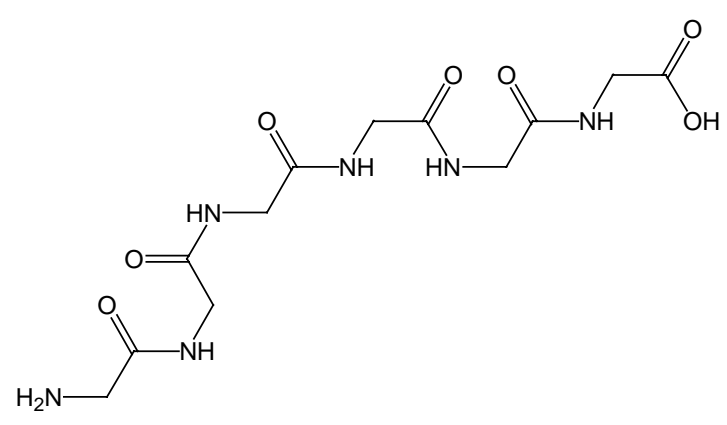


Scheme 5. Structure of Try-Leu (YL)

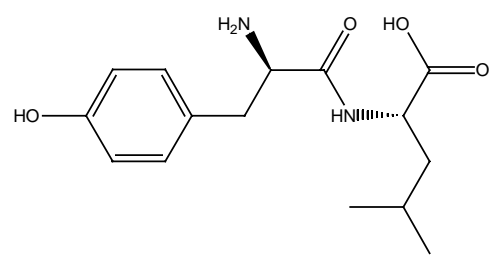

